\title{
Approach for multiscale modeling the thermomechanical tool load in gear hobbing
}

\author{
Nico Troß ${ }^{1}\left[D\right.$ · Jens Brimmers ${ }^{1}$. Thomas Bergs ${ }^{1,2}$ \\ Received: 24 March 2021 / Accepted: 29 July 2021 / Published online: 15 September 2021 \\ (c) The Author(s) 2021
}

\begin{abstract}
In this report, an approach is presented how a geometric penetration calculation can be combined with FE simulations to a multiscale model, which allows an efficient determination of the thermomechanical load in gear hobbing. FE simulations of the linear-orthogonal cut are used to derive approximate equations for calculating the cutting force and the rake face temperature. The hobbing process is then simulated with a geometric penetration calculation and uncut chip geometries are determined for each generating position. The uncut chip geometries serve as input variables for the derived equations, which are solved at each point of the cutting edge for each generating position. The cutting force is scaled according to the established procedure of discrete addition of the forces along the cutting edge over all individual cross-section elements. For the calculation of the temperature, an approach is presented how to consider a variable chip thickness profile. Based on this, the temperature distribution on the rake face is calculated. The model is verified on the one hand by cutting force measurements in machining trials and on the other hand by an FE simulation of a full engagement of a hob tooth.
\end{abstract}

\section{Ansatz zur Mehrskalenmodellierung der thermomechanischen Werkzeugbelastung beim Wälzfräsen}

\section{Zusammenfassung}

In diesem Bericht wird ein Ansatz vorgestellt, wie eine geometrische Durchdringungsrechnung mit FE-Simulationen zu einem Mehrskalenmodell kombiniert werden kann, welches eine effiziente Ermittlung der thermomechanischen Belastung beim Wälzfräsen ermöglicht. Aus FE-Simulationen des Linear-Orthogonalschnitts werden Näherungsgleichungen zur Berechnung der Schnittkraft und der Spanflächentemperatur abgeleitet. Anschließend wird der Wälzfräsprozess mit der geometrischen Durchdringungsrechnung simuliert und so die Spanungskenngrößen für jede Wälzstellung ermittelt. Die Spanungskenngrößen dienen als Eingangsgrößen für die abgeleiteten Gleichungen, welche an jedem Punkt der Schneidkante für jede Wälzstellung gelöst werden. Die Zerspankraft wird nach dem etablierten Verfahren der diskreten Addition der Kräfte entlang der Schneidkante über alle einzelnen Querschnittselemente skaliert. Für die Berechnung der Temperatur wird ein Ansatz zur Berücksichtigung eines variablen Spanungsdickenverlaufs vorgestellt. Darauf aufbauend wird die Temperaturverteilung auf der Spanfläche berechnet. Das Modell wird einerseits durch Kraftmessungen in Zerspanversuchen und andererseits durch eine FE-Simulation eines vollen Eingriffs eines Wälzfräserzahns verifiziert.

Availability of data and material Due to ongoing studies, the data associated with the publication is currently not available.

Code availability Due to ongoing studies, the code associated with the publication is currently not available.

Nico Troß

n.tross@wzl.rwth-aachen.de

1 WZL, RWTH Aachen University, Campus-Boulevard 30, 52074 Aachen, Germany

2 Fraunhofer IPT, Steinbachstraße 17, 52074 Aachen, Germany

\section{Introduction}

Gear hobbing is an established gear manufacturing process and is widely used in the wind power, automotive, aerospace and general engineering applications [1]. For the evaluation of the tool load and the interpretation of the wear behavior, uncut chip geometries such as the maximum uncut chip thickness are often used [2-5]. Due to the complexity of the hobbing kinematics and chip formation, numerical penetration calculation software such as SPARTApro [3, 4], FRS/MAT [5] or HOB3D [6] have to be used for the de- 
Fig. 1 FE model of the linearorthogonal cut and parameter space
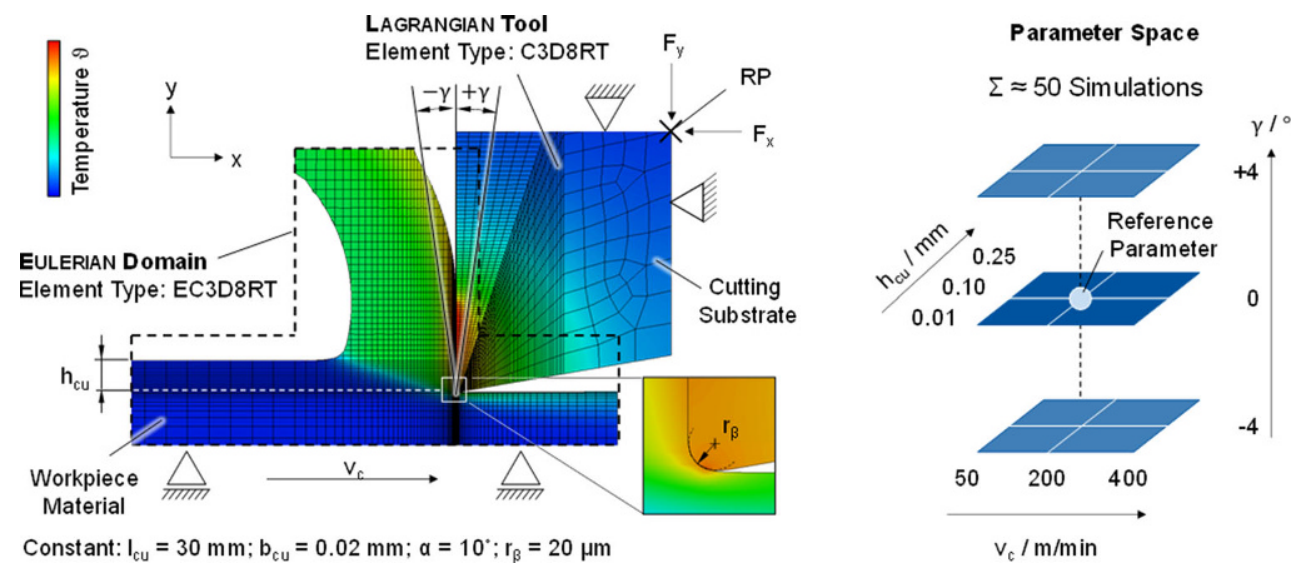

termination of the uncut chip geometries. The disadvantage of the geometric approach is the insufficient description of the contact conditions between tool and workpiece. Material properties, cutting speed, cutting edge shape as well as the (effective) rake and clearance angles have no influence on the uncut chip geometry.

To take physical properties into account, researchers have extended the penetration calculation by empirical and analytical models. On the one hand, cutting force models have been developed to predict the resulting force components for the hobbing process [7, 8]. The forces are calculated based on the uncut chip thickness from the penetration calculation and empirical coefficients determined in machining trials. On the other hand, models for the prediction of cutting forces and mean rake face temperatures using an analytical formulation of the orthogonal cut have been reported $[9,10]$.

For a detailed analysis of the thermomechanical load in the gear hobbing process, Finite Element Analysis (FEA) was applied in recent studies. Bouzakis et al. used the FE software Deform 3D to analyze the chip formation [11, 12], the cutting forces [12] as well as the tool stresses [13]. Liu et al. studied the thermomechanical load of a cutting engagement for rack and pinion milling [14], while Dong et al. analyzed the tool wear [15]. Karpuscheski et al. reported on the influence of different tool profiles on the cutting temperature in individual generating positions using the FE software AdvantEdge [16, 17]. Due to the high computational time required for the simulation, the aforementioned FE simulations were usually limited to the interaction of only one tooth with the workpiece material. To evaluate the load collective of the entire process, all generating positions would have to be simulated, which would exponentially increase the required simulation time. For an efficient analysis of the full hobbing process, a method is required which allows the analyzation of the thermomechanical tool load for all generating positions within a reasonable simulation time.
The aim of this work is to predict the thermomechanical tool load in gear hobbing by means of a multiscale model. The model combines the uncut chip geometries from a geometric penetration calculation (macro scale) with thermomechanical load and state variables from FE simulations of the orthogonal cut (micro scale). Cutting speed, uncut chip thickness and rake angle are varied within a defined parameter space in FE simulations using Abaqus/CAE. Cutting forces and rake face temperatures are obtained from the simulation based on the workpiece material behavior as well as the contact conditions at the tool/chip interface. Functional relationships between the obtained thermomechanical quantities and the variation parameters are deducted. The hobbing process is then simulated by means of the geometric penetration calculation SPARTApro and the uncut chip geometries are determined for each generating position. To calculate the cutting force and temperature profile, the determined approximate equations are solved at every discrete point of the cutting edge for each generating position based on the local uncut chip geometries. The result is a multiscale model for describing the thermomechanical tool load in each generating position.

\section{Analysis of the thermomechanical load in the linear-orthogonal cut}

\subsection{Setup and conditions of the simulation}

The simulation was carried out by means of a thermomechanically coupled, explicit FE model of the linear-orthogonal cut using the Coupled Eulerian-Lagrangian (CEL) formulation in Abaqus/CAE 6.14-6, Fig. 1. Similar models have been used by other researchers who validated the suitability of such a model to represent the orthogonal cut [18-20].

The workpiece material domain was discretized by the Eulerian formulation using EC3D8RT elements, while the 
Table 1 Mechanical and thermal properties of cutting and workpiece material at $20^{\circ} \mathrm{C}$

\begin{tabular}{lll}
\hline & Cutting substrate & Workpiece material \\
\hline Young's modulus $E[\mathrm{MPa}]$ & 600,000 & 213,900 \\
Density $\varrho\left[\mathrm{kg} / \mathrm{m}^{3}\right]$ & 15,000 & 7850 \\
Thermal conductivity $k\left[\mathrm{~W} /\left(\mathrm{m} \cdot{ }^{\circ} \mathrm{C}\right)\right]$ & 68.90 & 48.03 \\
Specific heat capacity $c\left[\mathrm{~J} /\left(\mathrm{kg} \cdot{ }^{\circ} \mathrm{C}\right)\right]$ & 213 & 440 \\
\hline
\end{tabular}

Table 2 JC parameters for casehardened steel $18 \mathrm{CrNiMo7}-6$ [18]

\begin{tabular}{llllllll}
\hline$A$ & $B$ & $\vartheta_{R}\left[{ }^{\circ} \mathrm{C}\right]$ & $\vartheta_{S}\left[{ }^{\circ} \mathrm{C}\right]$ & $n[-]$ & $m[-]$ & $C[-]$ & $\dot{\epsilon}_{0}[-]$ \\
{$[\mathrm{MPa}]$} & {$[\mathrm{MPa}]$} & & & & & & \\
\hline 281 & 521 & 20 & 1500 & 0.22 & 1.3 & 0.017 & 0.001 \\
\hline
\end{tabular}

stationary tool was meshed using C3D8RT elements with Lagrangian formulation. The smallest edge length was $l_{E}=6 \mu \mathrm{m}$ for the Eulerian domain and $l_{E}=2 \mu \mathrm{m}$ for the tool. The chip is formed by the continuous flow of the material through the Eulerian domain against the tool. Due to the fixed mesh, this method is insensitive to large deformations and no distortion of the elements occur [21].

Case-hardening steel 18CrNiMo7-6 was used as workpiece material and tungsten carbide as cutting substrate. The mechanical and thermal properties of the respective materials used for the simulation are shown in Table 1.

The thermomechanical workpiece material behavior was described according to the Johnson-Cook (JC) constitutive material law, Eq. 1 [22] :

$$
\begin{aligned}
\sigma_{F}(\epsilon, \dot{\epsilon}, \vartheta) & =\left(A+B \cdot \epsilon^{n}\right) \cdot\left(1+C \cdot \ln \frac{\dot{\epsilon}}{\dot{\epsilon_{0}}}\right) \\
& \cdot\left(1-\left[\frac{\vartheta-\vartheta_{0}}{\vartheta_{m}-\vartheta_{0}}\right]^{m}\right)
\end{aligned}
$$

where $\sigma_{F}$ is the flow stress, $\epsilon$ the equivalent plastic strain, $\dot{\epsilon}$ the plastic strain rate, $\dot{\epsilon}_{0}$ the reference strain rate, $\vartheta$ the current temperature and $\vartheta_{m}$ melting temperature. $A, B, C, n$ and $m$ are material constants determined in experiments at or below the transition temperature $\vartheta_{0}$. The constants are shown for a soft state case-hardening steel 18CrNiMo7-6 as a typical steel grade for gears in Table 2. The material constants were validated by Abouridouane et al. for an FE simulation of the orthogonal cut [18]. The simulations were performed using the same simulation environment and FE formulation as in the present case. It can therefore be assumed that the material model is also valid for the present case.

The friction at the tool/chip interface was described by the Couloumb friction law at a constant coefficient of friction of $\mu=0.4$. The fraction of plastic work converted into heat was considered by a Quinney-Taylor coefficient of $\beta=0.9$ and the thermal contact by a contact heat transfer coefficient of $h_{t}=10^{4} \mathrm{~W} /\left(\mathrm{m}^{2} \cdot{ }^{\circ} \mathrm{C}\right)$ [21, 23].

The uncut chip thickness was varied in the range of $0.01 \leq h_{c u} \leq 0.25 \mathrm{~mm}$, the cutting speed in the range of
$50 \leq v_{c} \leq 400 \mathrm{~m} / \mathrm{min}$ and the rake angle by $\gamma=0^{\circ} \pm 4^{\circ}$, Fig. 1 . The chosen ranges represent common values for gear hobbing of small to medium sized gears made of case-hardening steel. The parameter combination $v_{c}=200 \mathrm{~m} / \mathrm{min}$, $h_{c u}=0.1 \mathrm{~mm}$ and $\gamma=0^{\circ}$ was used as reference. Since the simulation can be evaluated at different time increments, the uncut chip length was kept constant at $l_{c u}=30 \mathrm{~mm}$. The cutting edge radius and the uncut chip width were $r_{\beta}=20 \mu \mathrm{m}$ and $b_{c u}=0.02 \mathrm{~mm}$. The clearance angle was $\alpha=10^{\circ}$. The evaluation of the cutting force $F_{c}$ was performed at the tool reference point (RP) in $x$-direction and the evaluation of the temperature $\vartheta$ along the rake face at different time increments of the simulation.

\subsection{Modeling of the cutting force}

In the simulation, the cutting force $F_{c}$ corresponds to the force component acting on the tool in $x$-direction. The force was averaged over 200 time increments and divided by the uncut chip width $b_{c u}=0.02 \mathrm{~mm}$ to form the specific cutting force $F_{c}^{\prime}$.

The specific cutting force $F_{c}^{\prime}$ decreased with increasing cutting speed $v_{c}$ due to thermal softening of the workpiece material, Fig. 2. With increasing uncut chip thickness $h_{c u}$, a linear increase of the cutting force can be observed as a result of the increasing uncut chip cross section. A negative rake angle resulted in a higher specific cutting force than a positive rake angle, which can be attributed to an increasing plastic deformation with decreasing rake angle. The observed effects are in accordance with acknowledged machining theory such as Merchants shear plane theory [24].

Based on the simulations, a regression model for the specific force was parameterized following the basic Kienzle model by assuming a steady-state process [25]. The influence of the uncut chip thickness and the cutting speed is described as a power function and the influence of the rake angle as an exponential function. The modeled specific cutting force $F_{c \text {,mdl }}^{\prime}$ matches the simulated specific cutting force $F_{c \text {,sim }}^{\prime}$ with a coefficient of determination of $R^{2}=0.9894$ 
Fig. 2 Influence of the variation parameter on the specific cutting force

Fig. 3 Course of temperature along the rake face and over time
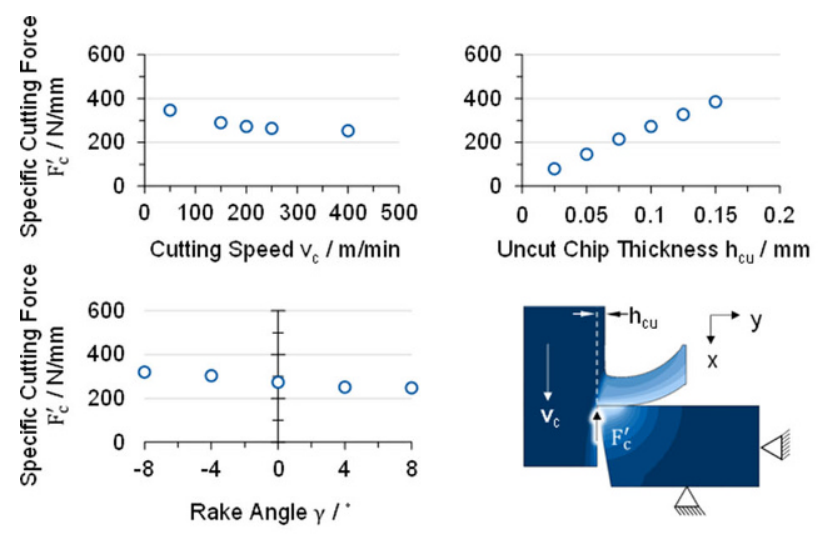

Reference Parameter: $v_{c}=200 \mathrm{~m} / \mathrm{min} ; h_{c u}=0.1 \mathrm{~mm} ; a=10^{\circ} ; y=0^{*} ; b_{c u}=0.02 \mathrm{~mm}$

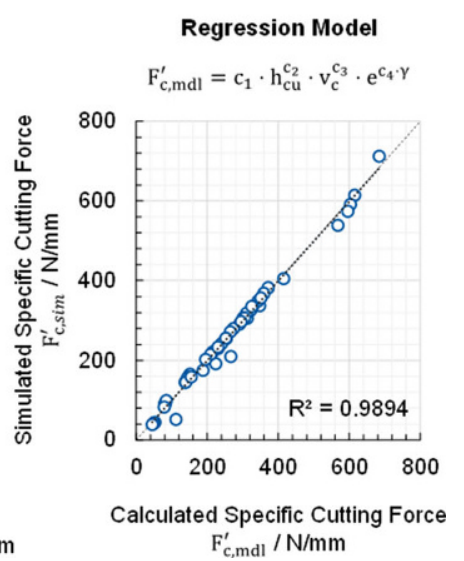

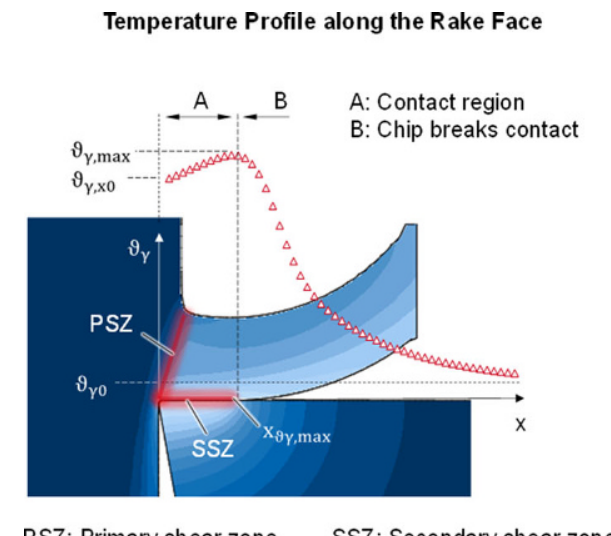

PSZ: Primary shear zone SSZ: Secondary shear zone

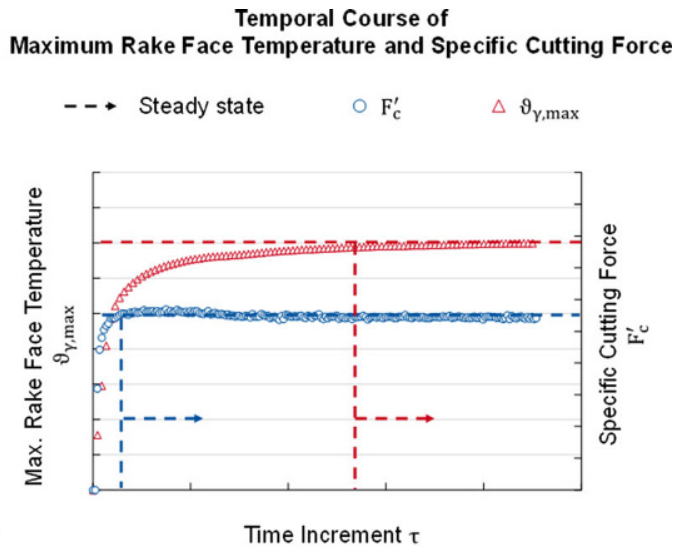

\subsection{Modeling of the temperature distribution on the rake face}

In contrast to the cutting force, the temperature was not determined as an average value of all time increments, but as a function of time and rake face position. The recorded temperature profile starts at $x=0$, which was defined as the location where the curvature of the cutting edge radius changes into the straight line of the rake face, Fig. 3. The temperature profile over the curvature of the cutting edge radius was not considered.

Most of the power consumed in machining is converted into heat. The power $P_{c}$ required for metal cutting is given by Eq. 2:

$P_{c}=F_{c} \cdot v_{c}$

where $F_{c}$ is the cutting force and $v_{c}$ the cutting speed. The conversion of power into heat occurs in two principal regions of plastic deformation: The primary shear zone (PSZ) and the secondary shear zone (SSZ). The resulting temperature at the tool/chip interface is then given by the heating of the material passing through the heat sources at the shear zones. Starting with an initial temperature $\vartheta_{\gamma, x}$ at $x=0 \mathrm{~mm}$, the temperature increases almost linearly until reaching a maximum value and then decreases towards an asymptotic limit of $\vartheta_{\gamma, 0}$. The maximum temperature $\vartheta_{\gamma, \max }$ at the tool/chip interface occurs where the material leaves the SSZ at $x_{\vartheta \gamma, \max }$. [26].

In the area of the temperature rise, the chip and the tool are in contact. The temperature drops as the contact between chip and tool breaks. Compared to the cutting force, the temperature requires more time to change into a steady state. This transient behavior must be taken into account when modeling the temperature, since the temperature is otherwise overestimated at the beginning of the cut.

Temperature profiles as a function of the variation parameters are shown in Fig. 4. The influence of the rake angle $\gamma$ was not considered in this case, as only a minor influence of the rake angle on the temperature profile was found in initial simulations. Instead, the time dependency of the temperature was taken into account. An increase in the cutting speed led to a quantitative increase in the temperature due to a higher power consumption in the cutting process which is converted into heat. For a cutting speed of $v_{c}=50 \mathrm{~m} / \mathrm{min}$ and an uncut chip thickness of $h_{c u}=0.1 \mathrm{~mm}$, the maximum temperature $\vartheta_{\gamma, \max }$ was present directly at the cutting edge at $x=0 \mathrm{~mm}$. At cutting speeds of $v_{c}>150 \mathrm{~m} / \mathrm{min}$, the position of the maximum temperature was shifted towards the rake face. When cutting at low speeds, sliding contact be- 
Fig. 4 Comparison of modeled and simulated temperature profiles

Fig. 5 Procedure for scaling the cutting force and temperature to the macro scale
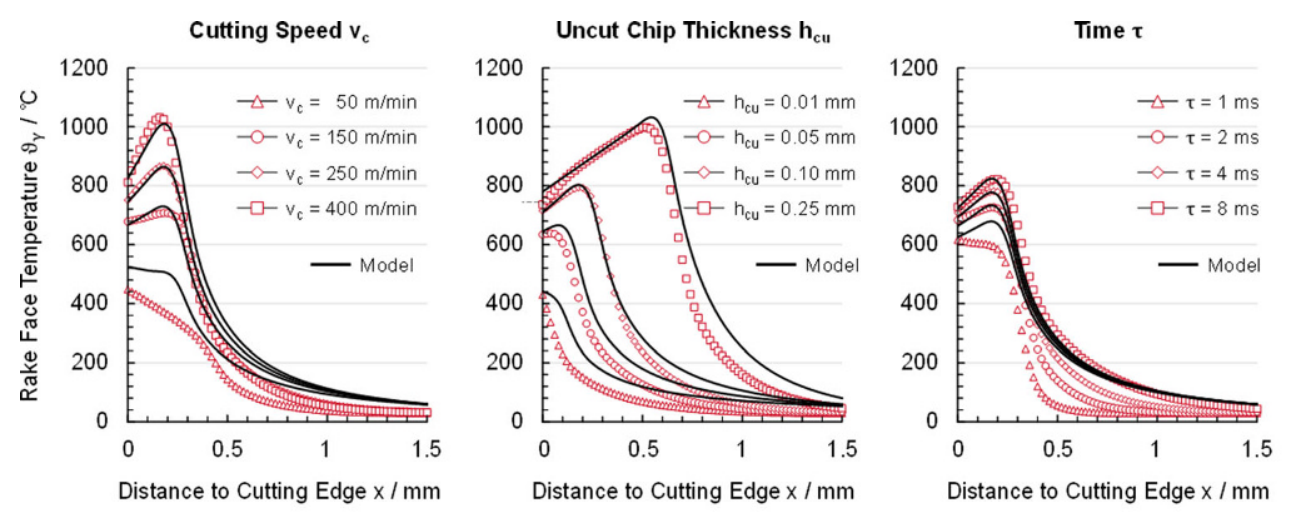

Reference Parameter: $v_{c}=200 \mathrm{~m} / \mathrm{min} ; b_{c u}=0.02 \mathrm{~mm} ; h_{c u}=0.1 \mathrm{~mm} ; a=10^{\circ} ; \gamma=0^{\circ} ; \tau=5 \mathrm{~ms}$

Temperature at Cutting Edge

$\vartheta_{\gamma, \mathrm{x} 0, \mathrm{mdl}}=\left[\mathrm{a}_{1}-\mathrm{e}^{\mathrm{h}_{\mathrm{cu}}}\right] \cdot \mathrm{a}_{3} \cdot \mathrm{v}_{\mathrm{c}}^{\mathrm{a}_{4}} \cdot \tau^{\mathrm{a}_{5}}$

\section{Maximum Temperature}

$\vartheta_{\gamma, \text { max,mdl }}=\mathrm{b}_{1} \cdot \mathrm{h}_{\mathrm{cu}}^{\mathrm{b}_{2}} \cdot \mathrm{v}_{\mathrm{c}}^{\mathrm{b}_{3}} \cdot \tau^{\mathrm{b}_{4}}$

Position of Maximum Temperature

$$
\mathrm{x}_{\vartheta \gamma, \max , \mathrm{mdl}}=\mathrm{c}_{1} \cdot \mathrm{h}_{\mathrm{cu}}^{\mathrm{c}_{2}}
$$

Discretization of Cross Sections

Cutting Force

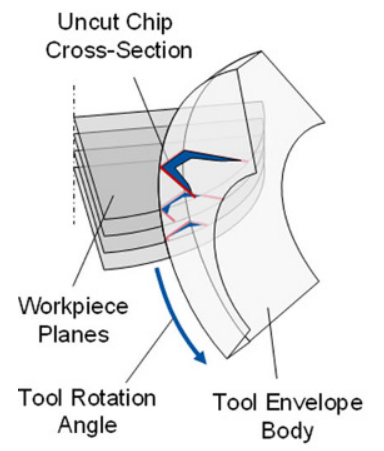

$\mathrm{F}_{\mathrm{c}}=\mathrm{f}\left(\mathrm{h}_{\mathrm{cu}}, \mathrm{v}_{\mathrm{c}}, \gamma\right) \quad \vartheta_{\gamma}=\mathrm{f}\left(\mathrm{h}_{\mathrm{cu}}, \mathrm{v}_{\mathrm{c}}, \mathrm{x}, \tau\right)$
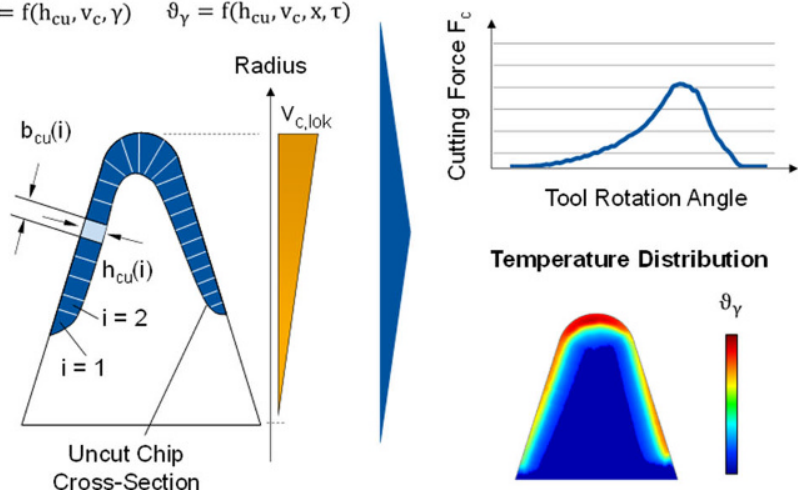

Temperature Distribution

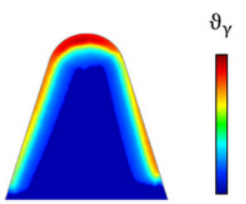

tween tool and chip may be dominant at the tool/chip interface, while at higher cutting speeds, a flow-zone is observed where the chip is seized to the rake face [27]. Depending on the contact conditions at the tool/chip interface, the mode of heat generation and the temperature distribution can differ. Essentially, at low cutting speeds, the rate of heat generation due to plastic deformation in the PSZ is higher than the rate of heat generation in the SSZ due to friction and thus no further increase in temperature occurs at the tool/ chip interface.

An increase in the uncut chip thickness led to an increase in the temperature, as well as to an increase in the distance between the position of the maximum temperature and the cutting edge. The higher temperatures can be attributed to the increasing cutting force (cf. Fig. 2), that is required for the machining of larger cross-sections, and therefore to a higher energy which is converted into heat. The extension of the heated area further from the edge is due the increase in the contact length between tool and chip. With increasing cutting time the temperature increases and approaches a stationary state.
Approximate equations for calculating the temperature $\vartheta_{\gamma, x 0}$ at $x=0 \mathrm{~mm}$, the maximum temperature $\vartheta_{\gamma \cdot \max }$ and the position of the maximum temperature $x_{i \gamma, \max }$ were developed, Fig. 4. For the calculation of the complete profile, the temperature between $\vartheta_{\gamma, x 0}$ and $\vartheta_{\gamma, \max }$, is approximated linearly, while the temperature drop is modeled using a power law. For the latter, it was assumed that the curve tends toward the ambient temperature.

For the calculation of the maximum temperature, the restriction was established that its location always occurs in distance to the cutting edge and is not affected by the cutting speed. Consequently, the location solely depends on the uncut chip thickness. This reduced the modeling effort while providing good agreement for most observations. The shortcoming of this approach is apparent at a cutting speed of $v_{c}=50 \mathrm{~m} / \mathrm{min}$. At this cutting speed, the maximum temperature was almost exclusively reached at the cutting edge, which led to incorrect values in the calculation. Since usual cutting speeds for hobbing soft state case-hardening steels are $v_{c}>150 \mathrm{~m} / \mathrm{min}$, the deviation at low cutting speeds can be regarded as negligible. Further deviations were observed for small uncut chip thicknesses of $h_{c u}<r_{\beta}$ and small time 
Fig. 6 Calculation of temperature with variable chip thickness profile

Fig. 7 Calculation of temperature distribution on the rake face

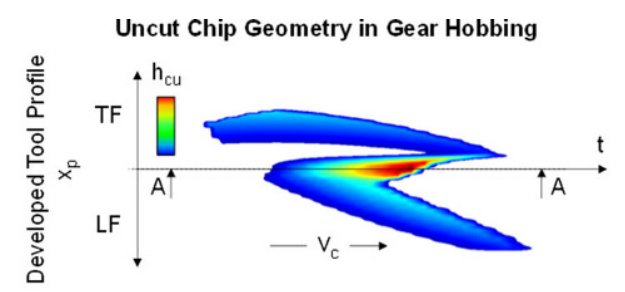

Temperature Curve with Variable Chip Thickness
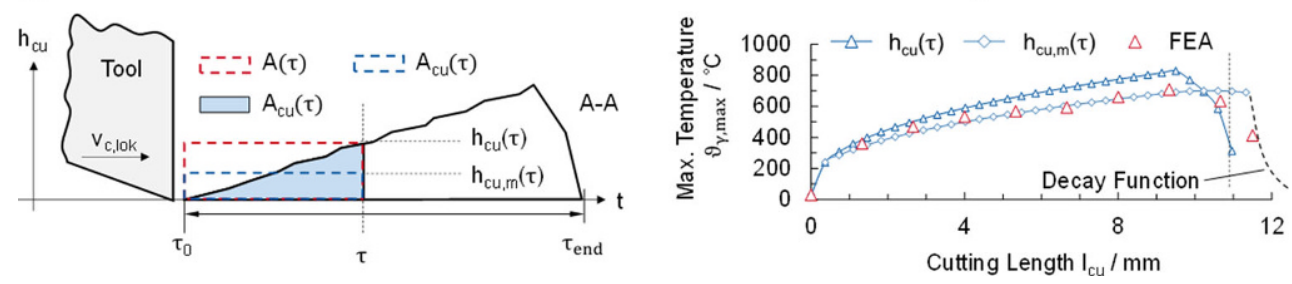

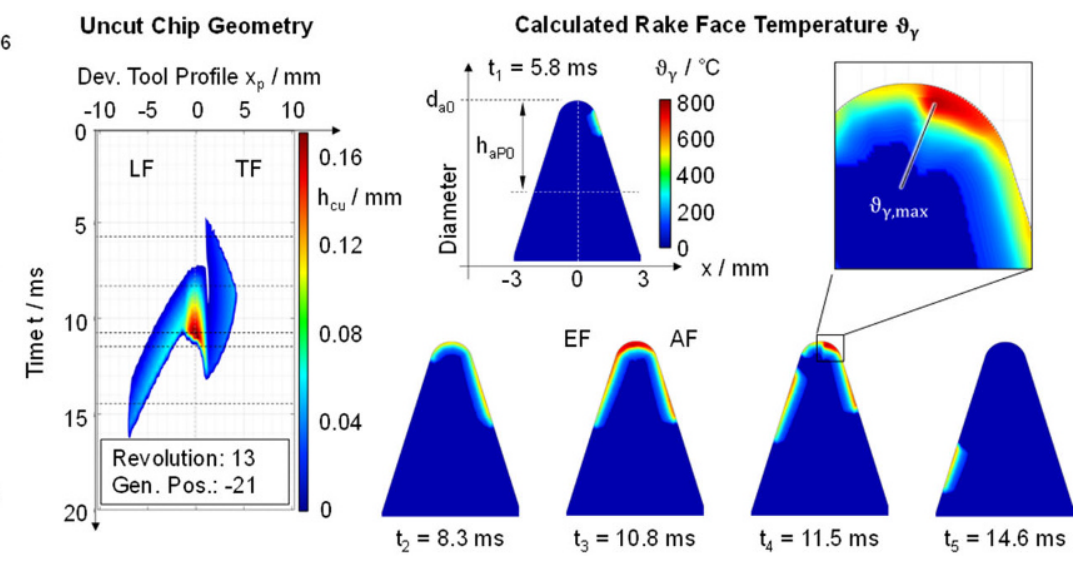

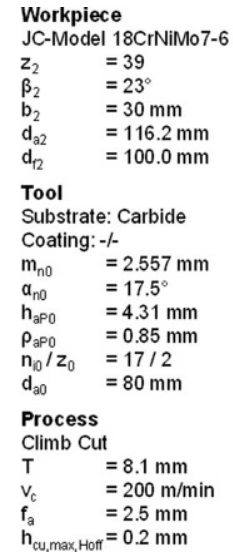

increments $\tau<2 \mathrm{~ms}$. These deviations could become more relevant if high cutting speeds are used in the machining of small-module gears. Here, the model must be further optimized in the future.

\section{Coupling of the approximate equations with the penetration calculation}

The hobbing process was calculated with the manufacturing simulation SPARTApro based on a geometric penetration calculation. SPARTApro is an established simulation method for gear hobbing and has been used in various research activities [2-4]. The software abstracts the workpiece into a defined number of parallel planes, which are penetrated by the tool profile during the simulation of the machine kinematics, Fig. 5. The intersections between the tool envelope body and the workpiece planes represent discrete uncut chip cross-sections over the tool rotation angle. The uncut chip cross-sections have defined uncut chip thicknesses and widths along the cutting edge. The locally and temporally known uncut chip geometries are used as input variables for the equations developed in Sect. 2 .

The calculation of the resulting cutting force on the macro level was performed according to the established method of discrete addition of the forces along the cutting edge over all individual cross-section elements at a certain point of time [7, 8]. In the calculation, the local cutting speed $v_{c, l o k}$ at the cutting edge point must also be taken into account. The resulting cutting force is calculated for each point in time or tool rotation angle of the cut, resulting in a continuous force curve over the cutting engagement.

\subsection{Calculation of the temperature for variable uncut chip thickness profile}

In contrast to the cutting force, the prediction of the temperature at each cross-section element is more complex. On the one hand, the individual cutting time at each point of the cutting edge must be taken into account. On the other hand, the temperature varies across the rake face. Additionally, a variable uncut chip thickness profile and the transient behavior at the beginning of the cut must be considered.

For a typical uncut chip geometry, the procedure for temperature calculation is shown schematically in Fig. 6. The ordinate describes the tool profile on which the individual cutting edge increments $x_{p}$ are located. The profile is divided into a leading (LF) and a trailing flank (TF). The abscissa indicates the cutting time $t$ and the start of cut for each point of the cutting edge. The points of the cutting 
edge come into contact with the material at different times. This is taken into account by the time variable $\tau$, which represents the individual cutting time at the respective cutting edge position. The uncut chip thickness $h_{c u}$ at time $t$ at a point $x_{p}$ of the cutting edge can be derived from the color scale.

In a representative cross-section A-A $\left(x_{p}=0 \mathrm{~mm}\right)$, the cut starts at time $\tau_{0}$ and ends at $\tau_{\text {end }}$. To calculate the cutting force at any time $\tau$, the chip thickness $h_{c u}(\tau)$, calculated by the penetration calculation, is used. This approach is valid because the force transitions to a steady state almost instantaneously (cf. Fig. 3). The temperature, however, is subject to a stronger time dependence. If an arbitrary chip thickness is passed to the model at time $\tau$, it is assumed that this chip thickness has been present since the beginning of the cut. The use of the chip thickness $h_{c u}(\tau)$ at time $\tau$ would therefore lead to a larger uncut chip cross-section $A(\tau)$ than the actual uncut chip cross-section $A_{c u}(\tau)$. Since the uncut chip cross-section is proportional to the work done, the energy consumption and consequently the resulting temperature would be overestimated. For this reason, the mean chip thickness $h_{c u, m}(\tau)$, averaged from $\tau_{0}$ to $\tau$, is used. The model still assumes that the transferred chip thickness is present since the beginning of the cut. In this case, however, the area of the uncut chip cross-section is equal to the area of $A_{c u}(\tau)$. Therefore, the energy supplied to the system is comparable.

To verify whether the mean uncut chip thickness $h_{c u, m}(\tau)$ can be used for the discrete calculation of the temperature, an FE model with triangular uncut chip thickness profile was setup, (Fig. 6 top right). The boundary conditions as well as the material and contact model were used analogously to the FE model of the linear-orthogonal cut described in Sect. 2.1. The result of the simulation is compared to the calculated temperature profiles (Fig. 6 bottom right). It is evident that both a calculation with $h_{c u}(\tau)$ and with $h_{c u, m}(\tau)$ follow the qualitative course of the simulated temperature. The temperature profile calculated with the mean uncut chip thickness $h_{\text {cu,m }}(\tau)$ also shows a quantitative agreement with the simulated temperature curve. Towards the end of the cut, however, the calculated temperature does not drop as fast as in the simulation. In this case, better agreements with the first approach are observed.

Since the second approach adequately describes the temperature curve both qualitatively and quantitatively until shortly before the end of the cut is reached, it is used in all further considerations. To describe the rapid temperature drop towards the end of the cut, the temperature values are numerically reduced to ambient temperature by means of a decay function.

\subsection{Calculation of the temperature on the macro scale}

Analogous to the cutting force, the rake face temperature was calculated at explicit time increments $t$ based on discrete cross-section elements of the cutting edge. The local cutting speed $v_{c . l o k}$, the cutting time $\tau$ at which the cutting edge element is in contact and the mean uncut chip thickness $h_{c u, m}(\tau)$ serve as input variables. The temperature profile along the rake face was determined according to the procedure described in Sect. 2.3. For this purpose, the assumption was made that no interactions with neighboring cutting elements occur. Effects due to unfavorable chip formation at curved areas are also not considered by the model.

Fig. 7 shows the temperature calculation for an exemplary gear case with a normal module of $m_{n 2}=2.557 \mathrm{~mm}$ for a representative generating position. The rake face temperature is analyzed at five different time increments. At $t_{1}=5.8 \mathrm{~ms}$, the trailing flank (TF) is in contact with the workpiece. The average temperature at this time is $\vartheta_{\gamma, 1} \approx 400^{\circ} \mathrm{C}$. At $t_{2}=8.3 \mathrm{~ms}$, a larger area of the trailing flank as well as the tool tip are involved in the cutting process. After $t_{3}=10.8 \mathrm{~ms}$, the maximum uncut chip thickness is reached at the tip, resulting in temperatures of approximately $\vartheta_{\gamma, 3}=740^{\circ} \mathrm{C}$ in this region. The maximum temperature of $\vartheta_{\gamma, 4}=750^{\circ} \mathrm{C}$ is calculated in the region of the tip radius of the trailing flank at $t_{4}=11.5 \mathrm{~ms}$. The magnification of the corresponding area shows that the maximum value does not occur directly at the cutting edge, but at a distance to it. On the one hand, the fact that the highest temperature occurs at this point is due to the high average chip thicknesses machined with this cutting edge element. On the other hand, the additional long contact time of the element with the workpiece leads to a higher temperature. Cutting edge elements with higher chip thicknesses but short contact times exhibit lower temperature values. At $t_{5}=14.6 \mathrm{~ms}$, only the leading flank is in contact. Due to the low uncut chip thicknesses and comparatively short contact times, only low temperatures are present.

It can be concluded that the model is capable of calculating the temperature profile on the rake face with spatial and time resolution. As the thermal load strongly influences the tool wear, the knowledge of the temperature profile is extremely useful for tool wear predictions and process optimization. Compared to an FE simulation, the developed model requires significantly shorter calculation times (minutes instead of days) and can therefore be used to calculate the temperature profile for all generating positions in the hobbing process efficiently. By its nature, the model is only valid for the configured parameter range. In addition, as the chip formation is not actually simulated, deviations between the modeled temperature profile and by FE simulated 
Fig. 8 Setup of the fly-cutting trial and design of experiments

Fig. 9 Comparison of measured and calculated maximum torque
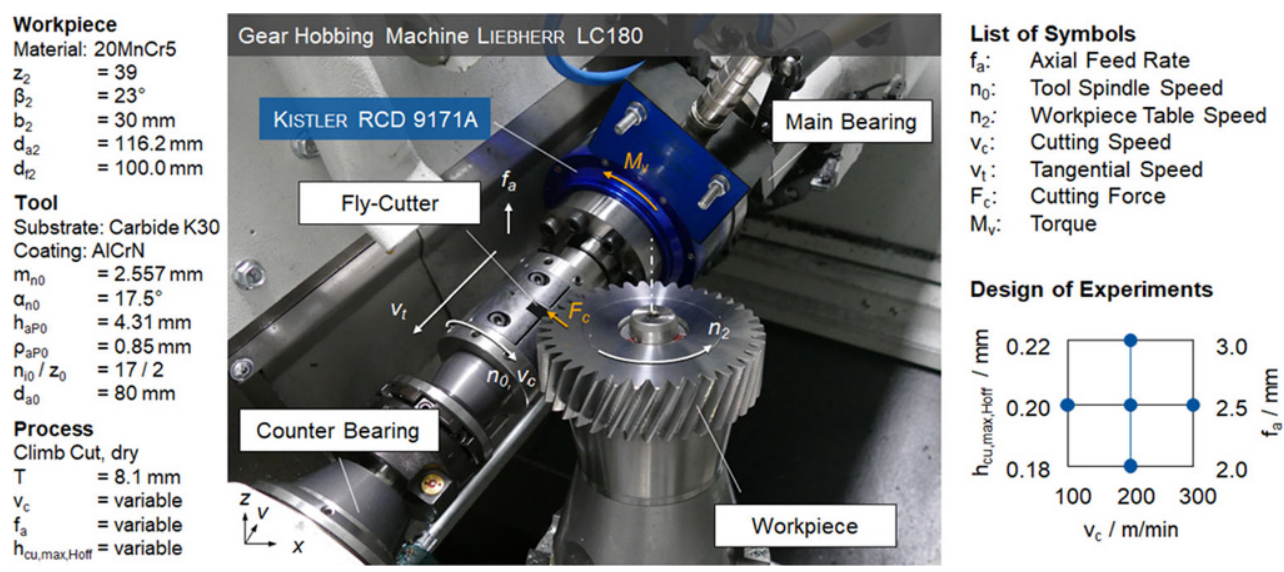

Workpiece

Material: $20 \mathrm{MnCr} 5$

$\mathrm{z}_{2}=39$

$=23^{\circ}$

$=30 \mathrm{~mm}$

$=116.2 \mathrm{~mm}$

$=100.0 \mathrm{~mm}$

Tool

Substrate: Carbide K30

Coating: AlCrN

$\mathrm{m}_{\mathrm{n} 0}=2.557 \mathrm{~mm}$

$\begin{array}{ll}\mathrm{m}_{\mathrm{n} 0} & =2.557 \\ \mathrm{a}_{\mathrm{n} 0} & =17.5^{\circ}\end{array}$

$\begin{array}{ll}\mathrm{a}_{\mathrm{n} 0} & =17.5^{\circ} \\ \mathrm{h}_{\mathrm{aP0}} & =4.31 \mathrm{~mm}\end{array}$

$\begin{array}{ll}\mathrm{h}_{\mathrm{aP0}} & =4.31 \mathrm{~mm} \\ \rho_{\mathrm{aP0}} & =0.85 \mathrm{~mm}\end{array}$

$\begin{array}{ll}\mathrm{n}_{10} / \mathrm{z}_{0} & =17 / 2 \\ \mathrm{~d}_{00} & =80 \mathrm{~mm}\end{array}$

Process

Process
Climb Cut, dry

Climb Cut, dry
$\mathrm{T} \quad=8.1 \mathrm{~mm}$

$\mathrm{v}_{\mathrm{c}} \quad=$ variable

$\mathrm{f}_{\mathrm{a}} \quad$ = variable

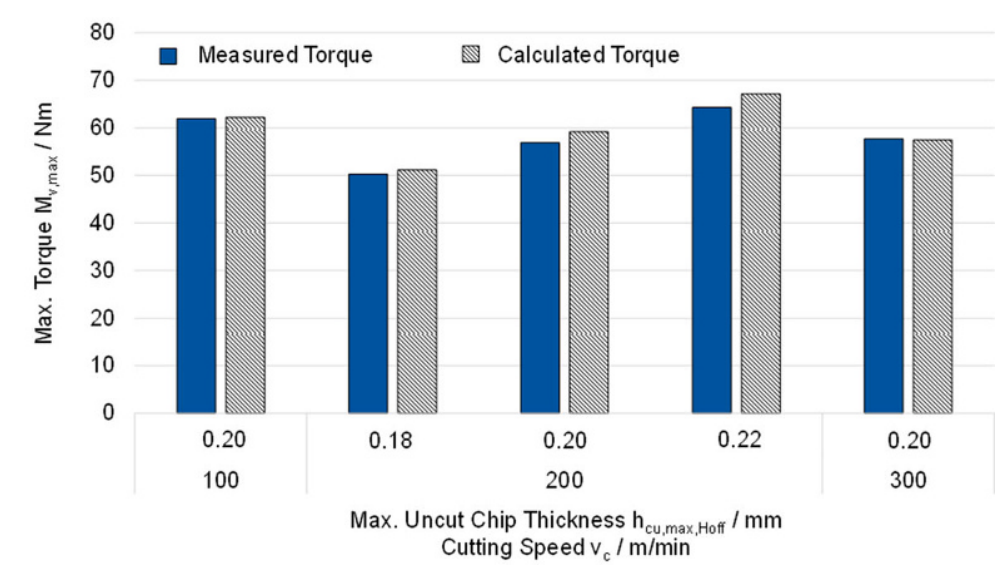

profile are to be expected. For further considerations, load collectives can be derived on the basis of the model, which describe the frequency of the occurring temperature values at critical points of the cutting edge or the rake face.

\section{Validation of the multiscale model}

For validation of the model, two methods were pursued: First, the calculation of the cutting force was verified in machining trials by means of the fly-cutting process. Second, the temperature distribution was compared to an FE simulation of a full engagement of a single hob tooth.

\subsection{Verification of the cutting force calculation in machining trials}

The calculation of the cutting force was verified by using force and torque measurements in the fly-cutting trial, Fig. 8. The fly-cutting trial represents an established analogy process to gear hobbing, where a single hob tooth reproduces all the generating positions of the corresponding hob by means of a continuous shift process [28]. The trials were carried out on a Liebherr LC180 gear hobbing machine. The cutting force $F_{c}$ and the torque $M_{v}$ were measured with a rotating multi-component dynamometer Kistler RCD 9171A, which was mounted between the tool and the main bearing. In the process, reaction forces occur at both the main and the counter bearing of the tool shaft, whereas the resulting torque around the tool axis is absorbed only by the main bearing. Investigations by Klocke et al. also revealed interfering signals in the range of cutting forces during force measurements in the fly-cutting trial [29]. For this reason, the validation was carried out exclusively on the basis of the torque measurement.

Gear and tool geometry were the same as for the simulation. All trials were carried out in climb cut at dry cutting conditions. The cutting speed $v_{c}$ and the feed rate $f_{a}$ were varied. The resulting maximum uncut chip thickness $h_{c u, \text { max }, \text { Hoff }}$ was calculated according to Hoffmeister [3] from the feed rate $f_{a}$ and is specified in Fig. 8. The workpiece material was a case-hardening steel $20 \mathrm{MnCr} 5$. A detailed characterization of the material can be found in a recent study of Troß et al., where the exact same material batch was used for tool wear investigations [28]. The material used for the trials does not fully correspond to the casehardened steel $18 \mathrm{CrNiMo} 7-6$ on which the simulations are based. However, both materials have a comparable ferritic- 
Fig. 10 Setup of FE simulation of full cutting engagement

Fig. 11 Comparison of model and FE simulation
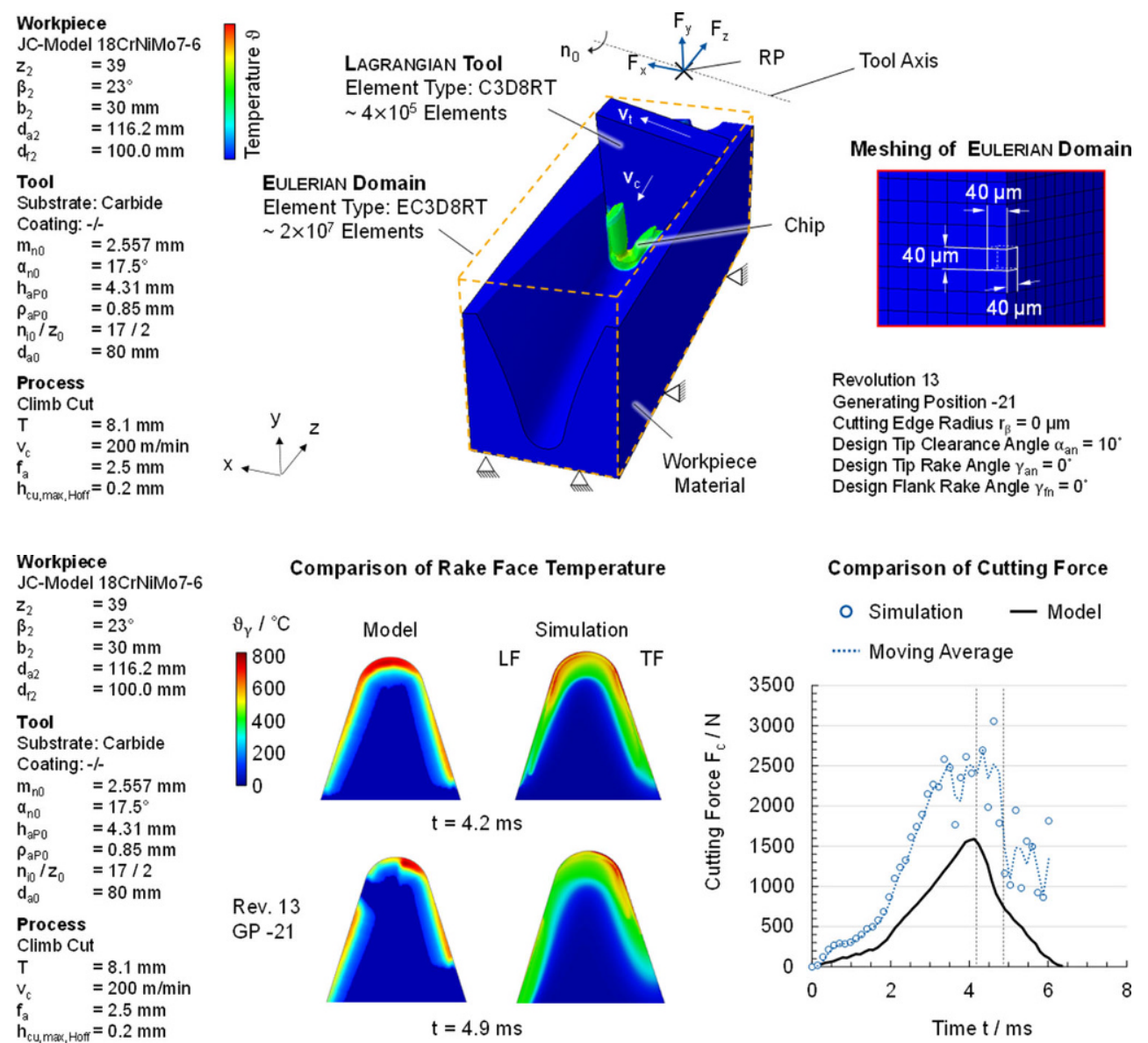

pearlitic material structure, cf. [18, 28], and mechanical and thermal properties, cf. $[30,31]$. Therefore, this comparison is considered sufficient. The tools used were separated from a WC-Co K30 carbide hob with an AlCrN coating.

The maximum torque of each test point was then calculated and compared to the maximum measured torque. The results are shown in Fig. 9. The calculated maximum torque $M_{v, \max }$ is in good agreement with the measured torque for all test points. A maximum deviation of approx. $4 \%$ was observed. The results confirm that based on FE simulations of the orthogonal cut, the cutting force can be reproduced. Despite that the material model deviates from the test material, a good agreement between model and simulation was achieved. In order to optimize the model, the material and contact laws for the material used in the machining trial must be parameterized in future experiments.

\subsection{Verification of the temperature calculation by FE simulation}

Due to the limited accessibility of the cutting zone in the fly-cutting trial, the verification of the temperature calculation was performed using an FE simulation of a full tooth engagement for the previously considered gear case,
Fig. 10. The model was created in Abaqus/CAE with thermomechanically coupled Eulerian-Lagrangian (CEL) formulation. All workpiece and cutting material parameters as well as contact conditions were chosen as for the orthogonal cut simulation (cf. Sect. 2.1). The tool rotates on its axis with a rotational speed $n_{0}$ and is simultaneously shifted along its axis at a tangential speed $v_{t}$. The translational motion reproduces the helix of the hob, while the rotational motion generates the cutting speed $v_{c}$. An ideal cutting edge with $r_{\beta}=0 \mu \mathrm{m}$ was assumed, as a cutting edge radius drastically increased the simulation time. The tip clearance angle was $\alpha_{a n}=10^{\circ}$ and the tip and flank rake angle were $\gamma_{a n}=\gamma_{f n}=0^{\circ}$.

At the beginning of the simulation, a part of the stationary Eulerian domain is assigned to the material in the form of the gap to be machined. The gap geometry of the considered generating position was extracted from the previously used penetration calculation SPARTApro and transferred to Abaqus/CAE in STEP file format. The relative position of the tool at the beginning of the cut was also taken from the penetration calculation. As the tool comes into contact with the material during the cutting movement, a chip is formed based on the implemented material and contact laws. 
A disadvantage of the CEL method is that the Eulerian domain and not the workpiece gap has to be meshed. This limits a local adjustment of the mesh resolution in the area of chip formation. Almost the entire Eulerian domain has to be meshed with the same resolution. With the considered element length of $l_{\mathrm{E}}=40 \mu \mathrm{m}$, approximately $4 \times 10^{7}$ elements would result for the Eulerian domain with uniform meshing. By partitioning, the number of elements were reduced to about $2 \times 10^{7}$ elements, which, however, still places high demands on the required computing power. The simulation was performed on 48 cores (Intel Xeon Platinum 8160 "SkyLake" 2.1 GHz) and required about two weeks of computing time. A resolution comparable to the simulation of the orthogonal cut with a smallest edge length of $l_{E}=6 \mu \mathrm{m}$ could not be reasonably realized with this method.

The comparison between the model and the FE simulation is shown in Fig. 11. For a representative generating position, temperatures at $t=4.2 \mathrm{~ms}$ and $t=4.9 \mathrm{~ms}$ as well as the course of the cutting force $F_{c}$ over the tool engagement are compared. Comparable maximum temperatures were obtained in the simulation, however, deviations regarding the temperature distribution can be observed. The stressed area of the rake face simulated by FE is larger than the one predicted by the model. In the simulation, a large portion of the rake face exhibits temperatures around $\vartheta_{\gamma}=400^{\circ} \mathrm{C}$. In the model, the temperature drops shortly after the cutting edge. The reason for this may be found in the chip formation, which deviates from the linear orthogonal cut. Since the chip cannot roll up unhindered, a larger area of the rake face is in contact with the chip. However, for the evaluation of the tool load only the maximum values are initially of interest. While the maximum temperature values are in good agreement, the position of the occurring maxima must still be verified in further investigations.

A significant difference can be observed in the comparison of the simulated and the modeled cutting force $F_{c}$. The simulated force exceeds the modeled value up to $70 \%$. In addition, the data points of the simulated cutting force show a strong scattering for $t>3 \mathrm{~ms}$. The reason for this can be found in the resolution of the Eulerian domain. During the tool engagement, small uncut chip thicknesses of $h_{c u}<40 \mu \mathrm{m}$ are present on the tool flanks (cf. also Fig. 7). Since the uncut chip thicknesses are smaller than the selected resolution of $l_{E}=40 \mu \mathrm{m}$, the forces are overestimated. In the area of the tool tip, a minor influence is to be expected, since uncut chip thicknesses of $h_{c u}>100 \mu \mathrm{m}$ predominate. As the cutting force significantly influences the resulting temperature, a reliable comparison of the rake face temperature is only possible if the simulated and modeled force agree. Therefore, the simulation must be further optimized in this respect. Finally, simulation and model have to be validated in machining trials.

\section{Summary}

A multiscale approach on how to describe the thermomechanical tool load in gear hobbing was presented. At the micro scale, FE simulations of the orthogonal cut were used to analyze the interaction of the cutting edge with the workpiece material. Equations for calculating the specific cutting force $F_{c}^{\prime}$ and the local rake face temperature $\vartheta_{\gamma}$ were derived. The deducted equations indicated good agreement with the simulation results. For the calculation of the temperature profile, deviations were observed for uncut chip thicknesses of $h_{c u}<r_{\beta}$ and for a cutting speed of $v_{c}=50 \mathrm{~m} / \mathrm{min}$ cut. For the present case, these deviations were negligible with regard to the focused gear size and the cutting speed range relevant for the material group. Depending on the application, further optimization may be required. For future investigations, additional parameters, such as the cutting edge radius or the coefficient of friction are to be included in the model consideration.

The macro scale was calculated with the geometric penetration calculation SPARTApro. This allowed a spatially and temporally resolved determination of the uncut chip geometries for each generating position. The uncut chip geometries were used as input variables for the derived approximate equations, which were solved at each point of the cutting edge for each generating position. The scaling of the cutting force was performed according to the established procedure of discrete addition of the forces along the cutting edge over all individual cross-section elements.

For the calculation of the temperature, an approach to consider a variable chip thickness profile by means of the mean uncut chip thickness $h_{c u, m}(\tau)$ was presented. Based on this, the temperature distribution on the rake face of a hob tooth in one generating position was calculated.

The verification of the calculated cutting force was carried out using torque measurements in the fly-cutting trials. A comparison of calculation and experiment showed good agreement. Since a material model deviating from the test material was used, further optimization potential is to be expected here.

Due to the limited accessibility of the cutting zone, the temperature distribution could not be verified in the fly-cutting trial. The model was therefore compared to an FE simulation of a full engagement of a hob tooth. Although CEL formulation is well-suited for the orthogonal cut, limitations in simulating a full tooth engagement were apparent. Even with a relatively large element size of $l_{\mathrm{E}}=40 \mu \mathrm{m}$, a great number of $2 \times 10^{7}$ elements were required for meshing the Eulerian domain. Since uncut chip thicknesses smaller than the applied element size are present on the tool flanks, forces up to $70 \%$ higher than calculated by the model were simulated. As the force significantly influences the resulting temperature, a reliable comparison of the rake face temper- 
ature was only possible to a limited extent. In future investigations, the FE model of the full tooth engagement must be further optimized.

Acknowledgements The authors gratefully acknowledge financial support by the WZL Gear Research Circle for the achievement of the project results

Funding The presented investigations were conducted as a part of a project sponsored by the WZL Gear Research Circle.

Funding Open Access funding enabled and organized by Projekt DEAL.

Conflict of interest N. Troß, J. Brimmers and T. Bergs declare that they have no competing interests.

Open Access This article is licensed under a Creative Commons Attribution 4.0 International License, which permits use, sharing, adaptation, distribution and reproduction in any medium or format, as long as you give appropriate credit to the original author(s) and the source, provide a link to the Creative Commons licence, and indicate if changes were made. The images or other third party material in this article are included in the article's Creative Commons licence, unless indicated otherwise in a credit line to the material. If material is not included in the article's Creative Commons licence and your intended use is not permitted by statutory regulation or exceeds the permitted use, you will need to obtain permission directly from the copyright holder. To view a copy of this licence, visit http://creativecommons.org/licenses/by/4.0/.

\section{References}

1. Karpuschewski B, Beutner M, Köchig M et al (2014) Gear hobbing-Research activities and state of the art. Adv Mater Res 1018:3-12. https://doi.org/10.4028/www.scientific.net/AMR.1018. 3

2. Troß N, Löpenhaus C, Klocke F (2019) Analysis of the cutting conditions for radial-axial infeed strategies in gear hobbing. Procedia CIRP 79:68-73. https://doi.org/10.1016/j.procir.2019.02.013

3. Brecher C, Brumm M, Krömer M (2015) Design of gear hobbing processes using simulations and empirical data. Procedia CIRP 33:484-489. https://doi.org/10.1016/j.procir.2015.06.059

4. Weck M, Klocke F, Winkel O et al (2003) Analysis of gear hobbing processes by manufacturing simulation. Ann Ger Acad Soc Prod Eng (WGP) 10:55-58

5. Bouzakis K-D, Lili E, Michailidis N et al (2008) Manufacturing of cylindrical gears by generating cutting processes: a critical synthesis of analysis methods. CIRP Ann Manuf Tech 57:676-696. https://doi.org/10.1016/j.cirp.2008.09.001

6. Dimitriou V, Vidakis N, Antoniadis A (2007) Advanced computer aided design simulation of gear hobbing by means of three-dimensional kinematics modeling. J Manuf Sci Eng 129:911-918. https:// doi.org/10.1115/1.2738947

7. Kühn F, Löpenhaus C, Klocke F (2016) Further development of a cutting force model for gear hobbing. Adv Mater Res 1140:165-172. https://doi.org/10.4028/www.scientific.net/AMR.1140.165

8. Bouzakis K, König W (1981) Process models for the incorporation of gear hobbing into an information centre for machining data. CIRP Ann Manuf Tech 30:77-82

9. Sabkhi N, Pelaingre C, Barlier C et al (2015) Characterization of the cutting forces generated during the gear hobbing process: spur gear. Procedia CIRP 31:411-416. https://doi.org/10.1016/j.procir. 2015.03.041
10. Sabkhi N, Moufki A, Nouari M et al (2020) A thermomechanical modeling and experimental validation of the gear finish hobbing process. Int J Precis Eng Manuf 21:347-362. https://doi.org/ 10.1007/s12541-019-00258-y

11. Bouzakis K-D, Friderikos O, Tsiafis I (2008) FEM-supported simulation of the chip formation and flow in gear hobbing of spur and helical gears. In: ICMEN (ed) 3rd International Conference on Manufacturing Engineering. Eigenverlag, Thessaloniki, pp 3-20

12. Bouzakis K-D, Friderikos O (2005) Determination of chip geometry and cutting forces in gear hobbing by a FEM-based simulation of the cutting process. In: Fraunhofer IWU (ed) 8th CIRP International Workshop on Modeling of Machining. Wissenschaftliche Scripten, Zwickau, pp 49-57

13. Bouzakis K-D, Vidakis N (1997) Effect of the mechanical stresses developed during gear hobbing on the fatigue failure of tool coatings. J Manuf Sci Prod 1:51-58

14. Liu W, Ren D, Usui S et al (2013) A gear cutting predictive model using the finite element method. Procedia CIRP 8:51-56. https:// doi.org/10.1016/j.procir.2013.06.064

15. Dong X, Liao C, Shin YC et al (2016) Machinability improvement of gear hobbing via process simulation and tool wear predictions. Int J Adv Manuf Tech 86:2771-2779. https://doi.org/10. 1007/s00170-016-8400-3

16. Karpuschewski B, Beutner M, Köchig M et al (2017) Cemented carbide tools in high speed gear hobbing applications. CIRP Ann Manuf Tech 66:117-120. https://doi.org/10.1016/j.cirp.2017.04. 016

17. Karpuschewski B, Beutner M, Köchig M et al (2017) Influence of the tool profile on the wear behaviour in gear hobbing. CIRP J Manuf Sci Technol 18:128-134. https://doi.org/10.1016/j.cirpj. 2016.11.002

18. Abouridouane M, Laschet G, Kripak V et al (2017) Cutting simulations of two gear steels with microstructure dependent material laws. Procedia CIRP 58:549-554. https://doi.org/10.1016/j.procir. 2017.03.332

19. Peng B, Bergs T, Klocke F et al (2019) An advanced FE-modeling approach to improve the prediction in machining difficult-tocut material. Int J Adv Manuf Tech 103:2183-2196. https://doi.org/ 10.1007/s00170-019-03456-0

20. Puls H, Klocke F, Veselovac D (2016) FEM-based prediction of heat partition in dry metal cutting of AISI 1045. Int J Adv Manuf Tech 86:737-745. https://doi.org/10.1007/s00170-015-8190-z

21. Puls H (2015) Mehrskalenmodellierung thermo-elastischer Werkstückdeformationen beim Trockendrehen. Diss., RWTH Aachen University

22. Johnson GR, Cook WH (1983) A constitutive model and data for metals subjected to large strains, high strain rates and high temperatures. In: Proceedings of the 7th international Symposium on ballistics, pp 541-547

23. Courbon C, Mabrouki T, Rech J et al (2014) Further insight into the chip formation of ferritic-pearlitic steels. Int J Mach Tools Manuf 77:34-46. https://doi.org/10.1016/j.ijmachtools.2013.10.010

24. Merchant ME (1945) Mechanics of the metal cutting process. I. Orthogonal cutting and a type 2 chip. J Appl Phys 267:267-275. https://doi.org/10.1063/1.1707586

25. Kienzle O (1952) Die Bestimmung von Kräften und Leistungen an spanenden Werkzeugen und Werkzeugmaschinen. VDI Z 94:299-305

26. Boothroyd G, Knight WA (2006) Fundamentals of machining and machine tools, 3rd edn. Mechanical engineering, vol 69. CRC Taylor \& Francis, Boca Raton

27. Trent E, Wright P (2000) Metal cutting, 4th edn. ButterworthHeinemann, Woburn

28. Troß N, Brimmers J, Bergs T (2021) Tool wear in dry gear hobbing of $20 \mathrm{MnCr} 5$ case-hardening steel, $42 \mathrm{CrMo} 4$ tempered steel 
and EN-GJS-700-2 cast iron. Wear. https://doi.org/10.1016/j.wear. 2021.203737

29. Klocke F, Schröder T, Schalaster R (2007) Cutting forces and tool wear in dry high-speed hobbing of different workpiece materials. In: Brecher C, Klocke F (eds) 2nd WZL Gear Conference in the USA. Eigenverlag, Aachen

30. Spittel M, Spittel T (2009) Steel symbol/number: 20MnCr5/1.7147. In: Martienssen W, Warlimont H (eds) Metal forming data of fer- rous alloys - deformation behaviour, 2C1. Springer, Berlin, Heidelberg, pp 1032-1037

31. Spittel M, Spittel T (2009) Steel symbol/number: 18CrNiMo7-6/ 1.6587. In: Martienssen W, Warlimont H (eds) Metal forming data of ferrous alloys-deformation behaviour, 2C1. Springer, Berlin, Heidelberg, pp 984-989 